\title{
Del Buen Vivir a la metrópolis latinoamericana: una aproximación a su sentido urbano.
}

\author{
Do Bom Viver à metrópole latino-americana: uma aproximação ao seu \\ sentido urbano. \\ Of the Good Live to the Latin metropolis-American: an approximation to \\ your urban sense.
}

\section{Rodrigo Antonio Cuevas Vargas ${ }^{1}$}

\begin{abstract}
Resumen
El Buen vivir/Vivir Bien se presenta como concepto y alternativa al desarrollo neoliberal que emerge en un contexto latinoamericano desde las cosmovisiones indígenas del Sumak Kawsay y el Suma Qamaña. En la emergencia de la actual crisis sistémica y civilizatoria en su escala global, presenta ciertos límites que surgen de su desplazamiento de las comunidades y territorios indígenas a esferas político administrativas o teórico académicas. El Buen Vivir se traslada así a un escenario urbano que materializa la producción y reproducción del capitalismo neoliberal, generando una brecha aparentemente irreductible entre sus principios y el lugar hacia el cual se desplaza. En este contexto surge el presente artículo, el cual busca contribuir a la discusión en torno al giro necesario que el Buen Vivir requiere para reflexionar en torno a las ciudades, su estructura, modos de vida, así como sus posibilidades de subversión. Se plantea que en el contexto urbano global actual, este concepto no se puede constituir como única alternativa de ruptura posible, por lo que necesariamente debe dialogar con otras propuestas/epistemologías levantadas desde otras latitudes y regiones del globo. Se considera que una discusión fértil es posible con el actual debate en torno a los Bienes Comunes en cuanto éste representa una perspectiva que converge en la búsqueda el horizonte común de pensar y superar la actual crisis civilizatoria.
\end{abstract}

Palabras clave: Buen Vivir; Bien común; metrópolis latinoamericana; crisis civilizatoria.

\section{Resumo.}

O Bom Viver/Viver bem se apresenta como conceito e alternativa ao desenvolvimento neoliberal que surge num contexto latino-americano desde as cosmovisões andina do Sumak Kawsay e Suma Qamaña. Na emergência da atual crise sistêmica e civilizatória em sua escala global apresenta alguns limites que surgem de seu deslocamento desde as comunidades e territórios indígenas, para esferas politico administrativas ou teóricas académicas. Neste contexto surge o presente artigo, o qual procura contribuir à discussão em volta as cidades, sua estrutura, modos de vida, assim como sua possibilidade de subversão. Se deixa ver que no atual contexto urbano global, este conceito não pode-se constituir como a única alternativa possível de ruptura, pelo que necessariamente ele deve dialogar com outras propostalepistemologias provenientes de outras latitudes $e$ regiões do globo. É considerado que uma discussão fértil é possível junto no atual debate em volta dos Bens Comuns, enquanto este representa uma perspectiva que converge no caminho de procura de horizonte comum de pensar e ultrapassar a crise civilizatória.

Palavras-chave: Bom Viver; Bem comum; metrópole latino-americana, crise civilizatória.

\section{Abstract.}

The Buen Vivir / Vivir Bien (Good living) is presented as a concept and alternative to the neoliberal development that has emerged in Latinamerica from the indigeneous cosmovisions of the Sumak Kawsay and the Suma Qamaña. In the emergence of the present systemic and civilizing crisis at a global scale, this concept

\footnotetext{
${ }^{1} \mathrm{Mg}$ (c) Geografia, UFPR. Curitiba, Paraná, Brasil; rodrigo.valdiarq@ gmail.com
} 
shows its limits that arise due to the desplacement from indigenous communities and territories to political, administrative, theoretical and academic spheres. The Buen Vivir moves to the urban setting which materializes the production and reproduction of neoliberal capitalism, creating an apparent insuperable gap between its principles and the place towards which it's going. It is in this context that the present paper emerges, seeking to contribute to the discussion about the necessary twist that the Buen Vivir requires to reflect about cities, its structure, ways of life, and possibilities for subversion. This paper states that in the current global urban context, it must dialogue with other epistemological proposals that have arisen in other latitudes and regions around the world. This work considers that a fertile dialogue is possible with the current debate about the Bienes Comunes (Commons), since it represents a perspective that converges in the search of thinking and overcoming the current civilizing crisis.

Key words: Buen Vivir ( Good living); Commons, Latin America metrópolis; civilizing crisis

\section{Introducción.}

El anclaje del urbanismo neoliberal en el espacio urbano ha llegado a un límite volviéndose insostenible para las grandes ciudades y sus ciudadanos. Problemáticas socio-espaciales, ambientales, políticas y económicas, acaban por situar la ciudad como un espacio de exclusión, desigualdad, de despolitización ciudadana, homogenización de las identidades y pérdida de los sentidos locales. Desde esta perspectiva, se hace necesario observar, analizar y cuestionar la ciudad como el hábitat construido por el hombre para su desarrollo. La vida humana en sus dimensiones espirituales, ambientales, sociales, política y materiales se concentra mayoritariamente en las metrópolis, por lo que podemos observar en su espacialidad tanto las contradicciones del modelo, como las resistencias que surgen en contraposición, tornándolo un espacio en disputa. Se propone una aproximación histórica al fenómeno de consolidación urbana en Latinoamérica y las consecuencias que ha provocado en su trayectoria, para proponer una reflexión camino a la construcción de un sentido urbano del Buen Vivir, reconociendo sus límites y posibles puentes de diálogo con otras alternativas sistémicas.

\section{Trayectoria y nuevos horizontes para pensar el Buen Vivir.}

Los estudios y reflexiones que se vienen dando en torno Buen Vivir a una década de que se instaló como propuesta para superar el paradigma de desarrollo y la actual crisis sistémica, dejan entrever tres corrientes que Vanhulst (2015) reconoce como "indigenista", "socialista" y "post-estructuralista".

La corriente indigenista como la primera y principal -pues es la matriz con la cual se consolidada- surge desde las comunidades indígenas de los Andes, que por medio del Sumak 
Kawsay Quechua y el Suma Qamaña Aymara, plantean una ruptura con el actual modelo de desarrollo, para situarse como una alternativa "al desarrollo" y no "de desarrollo". Esta propuesta está sustentada en los modos de vidas tradicionales y comunitarias, cuya matriz civilizatoria es milenaria, y tiene en su base el reconocimiento de la Pachamama como la Madre Tierra, es decir, el reconocimiento de la naturaleza como un ser viviente que contiene otras formas de vida en armonía con los humanos, la Pachamama como el todo. Esta perspectiva nos plantea además una visión cíclica y en espiral del espacio-tiempo (MACAS, 2014; SOLÓN, 2016.) como forma de ser y estar en el mundo. De esta forma la reproducción de prácticas sociales sustentadas desde una concepción indígena, escapa a la idea de desarrollo lineal de la racionalidad moderna colonial, desde allí que se reafirme que es una propuesta "al desarrollo".

Sin embargo, algunas precisiones deben ser revistas desde la categoría de lo "indigenista", pues bien como advierte Gudynas (2011), no se debe simplificar, reducir ni mucho menos atribuir el concepto del Buen Vivir al Sumak Kawsay o al Suma Qamaña, por una serie de argumentos. Primeramente estos conceptos se encuentran presentes en otros pueblos de Latinoamérica, como lo es el Kume Mongen del pueblo mapuche, el Teko Kavi del pueblo Guaraní, así como se puede reconocer el Buen vivir en otros grupos indígenas del amazonas brasilero. En segundo lugar, Además de encontrar otras expresiones similares, los pueblos indígenas sobrevivientes al proceso de colonización no se mantienen vivos en su forma precolonial, sino que han sido hasta el día de hoy, víctimas del proceso moderno/colonial (QUIJANO), lo que ha provocado que muchos rasgos y características de la sociedad capitalista/neoliberal hayan sido absorbidas y estén incorporados en sus formas de vida actual. Este hecho "cierra la puerta a aproximaciones románticas de dicha realidad" (ACOSTA, 2014). Otro punto a considerar, refiere a la construcción epistémica del Buen Vivir, que como concepto, no corresponde ni se utiliza en el lenguaje cotidiano o de las representaciones locales de las comunidades Aymaras, sino que su formulación ha sido producto del aporte de varios intelectuales indígenas y no indígenas, por lo que Uzeda (2009, Apud GUDYNAS, 2011) reconoce que es una recreación o innovación cultural. No por este hecho sin embargo, deja de ser indígena, y puede ser apropiada en su identidad (p.8). Así entonces, como resalta Acosta (2014) el Buen Vivir debe ser asumido como una categoría en permanente construcción y reproducción, por lo que su corriente indigenista no puede constituirse como un esencialismo atribuido a un imaginario fijo y caricaturesco de lo indígena. 
Desde una segunda perspectiva, el giro progresista Latinoamericano en la primera década del siglo XXI, en un esfuerzo por reconocer e incorporar aspectos del mundo rural e indígena en sus planes de desarrollo, utilizan el Buen Vivir/ Vivir Bien respectivamente, para situarlas como pilar fundamental de sus constituciones, materializado en los gobiernos de Ecuador (2008) y Bolivia (2009) dando paso a la corriente "socialista”. Así, el Buen Vivir/Vivir Bien es celebrado y visto en un comienzo como una posibilidad real de cambio de sentido y dirección en relación a la trayectoria histórica de despojo de recursos y riquezas sobre la cual se han construido los países colonizados en búsqueda de un imaginario de progreso y desarrollo (PORTO-GONÇALVES, 2014).

Sin embargo el camino recorrido hasta hoy por la vía socialista o progresista, ha demostrado ciertas distancias entre el proyecto inicial y el rumbo tomado. El progresismo en su camino de consolidación, como bien señala Marisela Svampa (2016) se ha nutrido y ha absorbido la energía creativa de diversos movimientos sociales y organizaciones que se vieron beneficiadas en sus demandas una vez consolidados los gobiernos. Esto trajo como consecuencia y al mismo tiempo, que dichos movimientos fueran perdiendo autonomía en el sentido de disminuir su capacidad de promover agendas políticas independientes del gobierno. Como reconoce Pablo Solón (2016) haciendo una lectura sobre el proceso constitucional en Bolivia, un error clave de los partidarios del Vivir Bien/Vivir Bien en su corriente pachamamista - o indigenista- fue el haber creído profundamente en potenciar el Estado como estructura que podría enfrentar el neoliberalismo, desconociendo de esta forma la lógica de poder que opera en él. De esta forma, al "estatizar" el Vivir Bien se empezó a horadar su poder autogestionario e interpelador (p.57). Así es como El Buen Vivir pasa a ser un concepto apropiado y direccionado desde una estructura nacional e institucional, que no sólo trajo la pérdida de la autonomía territorial, sino que además, demostró que la matriz económica desarrollista no ha mudado en lo absoluto, y por el contrario, tuvo una acentuación debido a un proceso de reprimarización de sus economías basadas en la explotación de sus recursos naturales (SVAPMA, 2011). Debido a estos hechos, el Buen Vivir/Vivir Bien pasa a ser vaciado en su sentido medular, perdiendo del carácter espiritual de reconocimiento de la Pachamama, su relación con los modos de vida y territorios que lo sustentan.

En una tercera línea definida como "post-estructuralista" estarían los debates teóricos y académicos que conservaría la esencia del Buen Vivir, y esta se inscribiría en torno a los debates de la modernidad/colonialidad, caracterizándose por ser en una línea moderada, abierta al dialogo con otras corrientes teóricas y epistemológicas, pero conservando sus 
elementos centrales, como la preservación de la naturaleza y la construcción conjunta del Buen Vivir no exclusiva del Sumak Kawsay (VANHULTS, 2015. p.250-252). Esta línea aproximaría y reconocería puentes entre el Buen Vivir y alternativas surgidas desde el pensamiento occidental, principalmente con las corrientes críticas que vienen cuestionando el modelo capitalista/neoliberal, tal como podría ser el Post-desarrollo (ESCOBAR 2004; GUDYNAS, 2014), y los actuales debates en torno a la Ecología Política y los Bienes Comunes. Si bien es cierto el Buen Vivir se constituye como un pensamiento y narrativa que rompe con la tradición de búsqueda de alternativas de desarrollo y sus múltiples apellidos (QUIJANO, 2000; ACOSTA, 2014), se concluye a modo general en los debates, que el Buen Vivir como concepto en construcción debe ser pensado desde la pluralidad e interculturalidad, entendiendo bajo este último concepto la definición de Catherine Walsh como "procesos de intercambio que permitan construir espacios de encuentro entre seres y saberes, sentidos y prácticas distintas" (2005). Así, el Buen vivir se constituiría como un campo epistémico, ontológico y práctico, que posibilite el encuentro de múltiples alternativas surgidas desde los márgenes del poder.

Como podemos observar, a pesar de que estas tres corrientes recorren diferente caminos, se encuentran en su base, imbricada y enlazadas, por lo que la discusión está lejos de agotarse y por el contrario, se encuentra en un rico y profundo debate. A partir de esta introducción muy general, se quiere hacer una aproximación hacia su sentido en el espacio urbano, pues como se reconoce en las palabras de Porto-Gonçalves (2009), el lugar de enunciación de los discursos no puede ignorar la materialidad de los lugares, la geograficidad de lo social y lo político. Siendo así entonces: ¿Dónde está su espacio de posibilidad más allá de los territorios indígenas que la sustentan en la práctica aislada; de las constituciones políticas que las enuncian en sus artículos; y del campo teórico que se preocupa por conceptualizarla?

\section{Paradigma del desarrollo y crisis en la ciudad Latinoamericana.}

El presente capitulo quiere presentar a modo general la trayectoria y los principales rasgos que hoy sitúan a la ciudad moderna/neoliberal en Latinoamérica como espacio en donde se manifiesta y expresa la crisis sistémica de la sociedad y el pensamiento occidental eurocéntrico. La búsqueda y el camino por alcanzar el ideal de desarrollo y progreso, sitúa a la ciudad como el principal espacio de producción y reproducción de las formas de vida que están asociadas a tal imaginario. Las ciudades como el espacio material y el hábitat construido 
por el hombre para su reproducción, o entendida también como la segunda naturaleza del hombre, evidencian en su estructura y las formas de vida que contiene, la contradicción o diferencia evidente, respecto a las formas ontológicas de vivir de los pueblos originarios y la idea del Buen Vivir.

\subsection{Trayectoria urbana, una breve aproximación.}

Nos encontramos con que el proceso histórico de construcción de las ciudades en América Latina, tuvo a partir del colonialismo uno de los pilares para la instauración del imaginario de modernidad. Este se caracterizaba como una ideología que se implementaba en la medida que integraba los distintos pueblos indígenas a su pensamiento moderno, y este los abrazaban a la civilización como sinónimo de liberación (MIGNOLO, 2003). Esta liberación de la sociedad se materializó así en la ciudad como nuevo símbolo de progreso social. De esta manera fue como la ciudad se constituyó un centro de poder y dominación que negaba la existencia del otro, del campesino, de lo rural, de lo indígena, alejándose de la naturaleza y lo natural en su concepción (RODRIGUEZ, 2013).

Independiente de que la ciudad como forma y estructura, desde una perspectiva decolonial sea históricamente y en primera instancia el lugar de la civilización que negó otras existencias (LANG, 2013); se reconoce desde los estudios urbanos que la ciudad como construcción histórica anterior a la actual crisis neoliberal, tenía ciertos valores y criterios urbanos que hacían de ella un espacio de encuentro y ciudadanía, tanto desde su perspectiva espacial como desde lo social (LEFEVBRE, 1968; BOOKCHIN, 1977; HARVEY, 2013; ).

En Europa, a partir de la revolución industrial, la ciudad se torna el centro de un nuevo protagonismo que las mantiene en una transición hasta el día de hoy y cubre casi la totalidad de la escala global, en términos de condensar en ellas la mayor parte de la población global. La explosión demográfica que acompaño este fenómeno hizo necesario ampliar los límites de la ciudad. Los arquitectos y urbanistas toman protagonismo ideológico al proyectar ciudades. Se proyectó su forma desde una perspectiva funcionalista y racional, surge el movimiento moderno en la arquitectura y la reproducción de tipologías formales eficientes para dar cabida a este fenómeno. El papel de los Congresos Internacionales de Arquitectura Moderna (CIAM) en la primera mitad del siglo XX marcó pautas mundiales de como pensar las ciudades y las viviendas.

Post segunda guerra mundial, estas ideas se consolidaran con aún más fuerza en los Estados Unidos y se aplicaron en la reconstrucción de Europa. Ejemplo claro del urbanismo expansivo 
de este periodo se dio en New York y tuvo al urbanista Robert Moses a la cabeza de la construcción en su imagen moderna, dando especial énfasis a la creación de autopistas que cortaban literalmente los barrios existentes. Una de las grandes críticas a su gestión provino a partir de la defensa del barrio de Greenwich, y tuvo a la activista Jane Jacobs (1964) como principal intelectual que fue capaz de hacer un análisis sensible sobre la riqueza y la diversidad que existía en la vida de barrio anterior a su modernización, que se manifestaban principalmente en el espacio público, con sus calles, veredas, plazas y parques.

El capitalismo, el consumo, los grandes edificios y el automóvil fueron iconos que marcaron esta idea de modernidad. A pesar de la crítica que acompañó al proceso de urbanismo moderno, ésta se configura como una teoría hegemónica que avanza sobre el presupuesto de desarrollo y modernidad, que se expande sobre la base de ignorar o matizar las diferencias locales. Si bien las ciudades en su proceso de expansión fueron incorporando las demandas de vivienda en su trama urbana, esta dio paso a los suburbios en sus márgenes, que no garantizaron el "derecho a la ciudad" identificado por Lefebvre en 1968 (LEFEBVRE, 2008; MARICATO, 2000).

Esta dinámica que se da en los países centrales de occidente, se comienza a expandir hacia Latinoamérica, orientando el modo de urbanismo de las principales capitales de los países de la región, que comienzan a experimentar un fenómeno similar, aunque con características particulares propias. Importante es señalar que el objetivo de avanzar hacia la modernización capitalista fue implantado directamente por los centros de poder global en las sociedades latinoamericanas como modelo a seguir a partir de la década de los 60 y 70 principalmente. La modificación de las estructuras urbanas también implicó una dominación sobre las formas de vida de las poblaciones, sus valores culturales, políticos y visiones de mundo (SANTOS, 1993; HARVEY, 2013). Las urbes comenzaron a replicar un patrón de crecimiento que se superpone sobre el tejido urbano existente, en términos de no reconocer las particularidades de los territorios y las sociedades, para imponer un sistema que busca reproducir un modelo de desarrollo meramente funcional, sustentada en una aspiración permanente y búsqueda del desarrollo asociada a un determinado estilo de vida, una idea de desarrollo y progreso enmarcada en rasgos espaciales homogéneos, caracterizados por el consumo, acumulación y distribución desigual de las riquezas (HARVEY, 2013; RODRIGUEZ, 2013; FARRÉS, MATARÁN, 2014). Este fenómeno es así reproducido por medio de la integración contextual de los proyectos de reestructuración neoliberal, tanto en la escala global, como en la escala 
nacional, regional y local definida por marcos institucionales y políticas estatales (BARROS, 2015).

\subsection{Neoliberalismo y la actual crisis en la ciudad global / latinoamericana.}

"El urbanismo como ideología formula todos los problemas de la sociedad en dimensiones de espacio, y sobrepone para términos espaciales todo lo que proviene de la historia, de la conciencia. Ideología que luego se desdobla. Una vez que la sociedad no funciona de manera satisfactoria, ¿será que no hay alguna patología en el espacio?" (LEFEBVRE, 2015.p.49). ${ }^{2}$

El urbanismo capitalista pasa a tener una corriente crítica desde la izquierda principalmente a partir de la reconocida obra de Lefebvre (1964) titulada "El derecho a la ciudad"; a partir de la cual se vienen problematizando algunos fenómenos como consecuencia del proceso de urbanización capitalista, siendo profundizado hasta su condición actual a escala global y latinoamericana.

Erminia Maricato (2000) en una perspectiva crítica y en un estudio sobre el caso Brasilero, más particularmente en el caso de São Paulo, identifica que como consecuencia del proceso de urbanización y modernización, la ciudad ha acabado por dividir su espacio urbano entre la "ciudad formal" y la "No ciudad". La primera es la población que reside en el centro de la ciudad y es beneficiada por la llegada de la modernidad y el progreso; y la segunda es la población a la cual se les ha negado la posibilidad de vivir en condiciones dignas de hábitat urbano, quedando en condiciones precarias debido a la pobreza, segregación urbana, exclusión, falta de una adecuada red de transporte, saneamiento, agua potable, áreas verdes e infraestructura que de soporte a la vida urbana, principalmente. Este análisis del fenómeno urbano, si bien hace referencia a São Paulo, es evidente en casi la totalidad de capitales y grandes ciudades de Latinoamérica, por lo que el análisis de la autora es pertinente para poder aproximarnos al fenómeno de la región.

Así es como capitalismo y urbanismo, en un proceso que tiene una relación dialéctica, torna el orden espacial como agente activo en la realización de determinadas acciones sociales sociedad de consumo-, y en donde ese orden al mismo tiempo es concebido como la condición para que esas acciones se produzcan -la producción del espacio- (GOMES, 2006). Como se viene señalando, este proceso provoca una creciente homogenización del espacio urbano que carece de sentido e identidad en relación a las particularidades del contexto histórico y geográfico. Este fenómeno de homogenización no sólo empieza a ser observado en la reproducción de las ciudades y su imagen, si no también se refleja en la esfera ciudadana,

\footnotetext{
2 Traducción libre del autor en base a la obra en portugués (2015).
} 
que comienza a perder las características de una sociedad políticamente diversa y activa que ya no utiliza su espacio público como espacio de apreciación y encuentro. De esta forma la ciudadanía y los individuos comienzan a transformarse en "pasivos espectadores" (GOMES, 2006) del mundo, siendo despojados de su condición crítica y política. Sus derechos pasan a ser substituidos por los privilegios que otorga el acceso a los servicios y bienes públicos, que sólo pueden ser adquiridos por quienes tienen la capacidad de pagar por ellos. El espacio público como componente fundamental de la trama urbana, y las personas como ciudadanos, comienzan a tener cada vez más una notoria "disolución, fragmentación y privatización" (BORJA; MUXI. 2000).

Neil Brenner (2015) señala que las múltiples discrepancias entre ideología y práctica, doctrina y realidad, visión y consecuencia que han acompañado la expansión transnacional del neoliberalismo $-\mathrm{y}$ las desigualdades que provoca- no son meros efectos secundarios accidentales, sino más bien algunos de sus rasgos más importantes (BRENNER et al. 2015, p.215). Las ciudades y su entorno, así como la ciudadanía en crisis no sólo se distingue desde el análisis de la perspectiva crítica, que sitúan al centro de la problemática al sistema y la lógica neoliberal sustentada en el aparato estatal y privado; sino que también por organismos que marcan las pautas de desarrollo futuro de las ciudades, tal como la ONU y su más reciente versión del hábitat III, acontecida en Octubre de 2016 en Bogotá, Colombia. En el foro se reconoce que "la persistencia de múltiples formas de pobreza, desigualdades crecientes y la degradación ambiental siguen siendo uno de los principales obstáculos para el desarrollo sostenible en todo el mundo" (ONU, A/conf.226/4, septiembre 2016) ${ }^{3}$. Ante este hecho, la nueva agenda adoptada señala pautas para pensar las nuevas ciudades del futuro, bajo la premisa de no dejar a ninguna ciudad atrás en su desarrollo, promoviendo economías urbanas sostenibles, con el objetivo de "lograr que las ciudades y los asentamientos humanos sean inclusivos, seguros, resilientes y sostenibles" (Ibíd.). Una de las principales críticas al foro, radica en no abordar en profundidad el sistema que provoca las desigualdades y patologías urbanas, sino por el contrario, sólo plantear soluciones con el objetivo de mitigar las consecuencias del modelo de desarrollo desigual, buscando alternativas "sustentables". El Manifiesto del hábitat alternativo, liderado por Jordi Borja (2016) sostiene que por el

\footnotetext{
3 Conferencia de las Naciones Unidas sobre la Vivienda y el desarrollo Urbano Sostenible -Hábitat III. Quito, Ecuador. 2016: http://www.habitat3.cl/wp-content/uploads/2016/10/Nueva-Agenda-Urbana-HabitatIII.pdf
} 
contrario, estos eventos legitiman el actual modelo, invisibilizando las verdaderas injusticias provocadas por el capitalismo. En ese sentido, mientras aún exista gente sin derechos no hay derechos de nadie. Si faltan los derechos se imponen los privilegios de las minorías (BORJA; CARRIÓN.2016).

El rechazo a las formas con las que viene operando el capitalismo salvaje, se da principalmente debido a la evidencia empírica que hoy visibiliza las contradicciones espaciales del modelo hegemónico, pues la acumulación capitalista va acompañada de una expansión sin límites de las ciudades, lo que conlleva una creciente segregación espacial y marginalización urbana, criminalización de la pobreza, inseguridad, homogenización de la vida, pérdida de las identidades locales, precarización de los espacios públicos, polución del ambiente, transformación de los ciudadanos en objetos de consumo y reproducción capitalista, entre otros.

En el actual debate crítico, se devela que el proyecto neoliberal no pretende en lo absoluto generar cambios radicales; y por lo tanto, estas sólo serían posibles desde rupturas estructurales que no estén vinculadas ideológicamente al sistema que reproduce las desigualdades en nombre del progreso; y que al mismo tiempo, este sustentada en un grupo humano consistente de ciudadanos, que actúe bajo nuevas lógicas de organización, para construir una sociedad políticamente activa en la búsqueda de la justicia social y la democracia.

Así es como las luchas por el derecho a la ciudad vienen siendo dadas por una gran cantidad de movimientos urbanos que buscan nuevos horizontes de posibilidad de ser y estar en la ciudad. Ejemplos claros en el último siglo XXI, principalmente a partir de la segunda década, han sido gatillados por diversas manifestaciones que con en el tiempo han re significado espacios urbanos, cristalizado alternativas serias y profundas en búsqueda de pensar la ciudad desde una nueva perspectiva, negando la condición capitalista/neoliberal. Encontramos en los Indignados de la plaza del Sol en 2011, la Plaza Syntagma de Grecia el 2011, el movimiento Occupy Wall Street, las manifestaciones de Passe Livre en el Brasil del 2013, las manifestaciones estudiantiles en Chile, uno de los puntos de no retorno en la construcción de alternativas que van más allá de la denuncia en las calle, que por otro lado, ha sido unos de los principales indicadores de la actual crisis sistémica. 


\section{Repensando las ciudades. Alternativas sistémicas en diálogo con el Buen Vivir.}

Boaventura de Sousa Santos (2010) reconoce muy bien la dificultad del pensamiento crítico en avanzar hacia imaginarios post-capitalistas y los límites que entrega el mismo capitalismo en la dificultad por imaginar un mundo sin él. Por lo tanto, para poder tener nuevas formulaciones se hace necesaria una aproximación desde el pensamiento occidental con el pensamiento que "no emerge de los término familiares de socialismo, derechos humanos, democracia o desarrollo, sino de dignidad, respeto, territorio, autogobierno, el buen vivir, la Madre Tierra". (p.17).

La ciudad global y las principales capitales de Latinoamérica están comenzando a espacializar propuestas y prácticas que tienen como base -y en contrapartida a la individualización de la vida mercantil- la colectividad y lo comunitario como estrategia de resistencia. Así, comienzan a ser rescatadas y reapropiadas prácticas comunitarias y solidarias, que tienen una dimensión inmaterial y subjetiva representada por las ideas de un nuevo mundo, que consiga resignificar el espacio urbano desde lo común, caminando hacia nuevas lógicas fuera del imaginario neoliberal. Por lo tanto, el desafío hoy, al cambiar la vida cotidiana desde las resistencias, va de la mano con lo que nos planteaba Lefevbre, al decir "cambiar la ciudad, cambiar la vida" (citado por BARROS, 2015) y que Harvey continua planteando al decir que no podemos pensar en cambiar la ciudad, sin divorciarnos de la idea de pensar qué tipo de personas queremos ser (HARVEY, 2013).

En el contexto latinoamericano eso puede ser una puerta de entrada a la incorporación de conceptos y prácticas que pueden oxigenar las luchas por la recuperación de la ciudad. Prácticas que sin embargo siempre han existido en el espacio no colonizado de Latinoamérica, el espacio rural y los márgenes urbanos, donde han sido resguardadas por las comunidades indígenas y campesinas que consiguieron mantener un cierto grado de autonomía -no sin una lucha permanente- del proceso de modernización/colonización.

Así entonces, el urbanismo neoliberal se encuentra con espacios de resistencia, donde son producidas y reproducidas prácticas re significadas de relaciones sociales, que tiene como objetivo disputar las lógicas de producción y reproducción de la sociedad de consumo, con este nuevo y al mismo tiempo antiguo mirar. Desde esta perspectiva el espacio público se torna como el espacio en disputa en primer grado. El espacio público cobra especial protagonismo en las nuevas luchas, por ser un espacio trasfigurados por el imaginario de los individuos que dirigen sus miradas y ven en la calle, la plaza o el parque, otra dimensión más 
allá de lo determinado como simple lugar de circulación y esparcimiento, para ser ocupado colectivamente y constituirse como un espacio de contestación política (POIRIER, 2015). Estas ocupaciones y manifestaciones se constituyen como un hecho concreto, que en la articulación, acción y permanencia en el tiempo de las acciones, se puede transformar en una fuerza de presión que en un largo plazo y por efecto acumulativo complejo, puede provocar alteraciones dignas de rupturas (LOPEZ DE SOUZA, 2007). Espacio público y territorio se presentan como categorías de análisis que ayudarían a pensar este fenómeno de reconquista social. La pregunta surgida desde la perspectiva del Buen Vivir, por lo tanto debiera caminar hacia el pensar una ciudad desde esta ruptura paradigmática que esté en sintonía con los fundamentos de ella, es decir, hacia una ciudad que pueda ser pensada como territorio de reproducción en armonía con los ciclos de la vida. ¿Hay cabida a esta posibilidad en la actual metrópolis latinoamericana?, ¿De qué forma pensar el Buen vivir desde un contexto urbano puede abrir alternativas y en qué escalas estas pueden operar? Movimientos de huertos comunitarios urbanos se expanden a una gran velocidad por el globo. La defensa por los parques, plazas, áreas verdes y ecosistemas urbanos son fundamentales para propiciar el encuentro con la naturaleza y las personas. La moneda Solidaria comienza a circular en espacios y lugares donde las relaciones capitalistas están agotadas; el arte urbano y los grafitis ayudan a crear estos espacios, discursos e imágenes colorean el gris cemento con imaginarios de otro mundo posible. Cada una de estas expresiones - y muchas otras más - contribuye y se complementan entre sí.

Los Bienes Comunes o el Procomún, se presenta en la actualidad como el giro más innovador desde la teoría crítica proveniente del pensamiento occidental. El cual al igual que el Buen Vivir, se presenta como un nuevo paradigma sustentado en las formas colectivas tanto de gerenciamiento de recursos (HARVEY, 2013; OSTROM, 1990) como de las relaciones sociales inmateriales en donde "los lazos comunes o comunitarios que hacen posible que los bienes materiales o inmateriales puedan ser en su sentido procesual, en beneficio del común/ o de lo comunitario", desde allí que plantea su visión de lo comunitario desde un "hacer comunidad”, o más bien "ser comunidad” (ZIBECHI, 2015. p.76).

\section{Conclusiones.}

El Buen Vivir pareciera ser una antítesis de las formas en cómo se habita la ciudad hoy en día, siendo considerada ésta incluso como la materialización del Mal Vivir (LANG, 2013). Así como el desarrollo no ha sido cuestionado en las diversas propuestas alternativas, sino por el 
contrario sólo fue redefinido en sus características más destacadas (ACOSTA, 2016), las ciudades tampoco han sido redefinidas ni cuestionadas en su trayectoria hacia su estado actual, más allá de la búsqueda para hacer de ellas más "sustentables". Como nos recuerda Delgado (2015), estas no serían suficientes si no parten de nuevos paradigmas a cerca tanto de la forma como de la función de los espacios construidos, y por lo tanto, al pensar en el Buen Vivir en su sentido Urbano, este no puede surgir del mero traslado del imaginario existente de dichas nociones en lo rural (Delgado, 2015.p. 48). Esto nos empuja a un necesario debate teórico que pueda estar sustentado en diversas prácticas, y al mismo tiempo en diálogo con las dinámicas y teorías globales.

En esta escala, estas luchas no se darían de forma conjunta y homogénea, si no que como se viene discutiendo, surgen desde movimientos sociales y ciudadanos que toman y reivindican espacios urbanos, principalmente de pequeña escala, en diálogo con propuestas que surgen en ciudades de todo el globo y territorios. En Latinoamérica, ¿Cómo puede entrar en el debate del cambio de paradigma y/o cambio civilizatorio, conceptos y prácticas del mundo indígena rural, si hoy la gran mayoría de la población -y grandes porcentajes de indígenas - se encuentran viviendo en ciudades, y ésta a su vez es producida y reproduce continuamente la lógica capitalista neoliberal? Por lo tanto, ¿cómo reinventar el soporte espacial de las relaciones dentro del contexto urbano, como nuevo hábitat que posibilite ese cambio?

Lo comunitario tanto en su sentido social de reproducción espacial, material, cultural, económico, simbólico y espiritual, así como territorio habitado por lo diverso, como espacio para que se realice el Buen Vivir y el Bien Común, tiene una particularidad que las posiciona frente a frente: no tienen valor monetario. Este es uno de los valores esenciales y fundamentales que aún no han sido arrebatados por el pensamiento hegemónico, por lo tanto su recuperación y expansión contribuye a la búsqueda de nuevos paradigmas de las ciudades. Considerando el gerenciamiento de recursos y espacios comunes dados por grupos determinados y autodefinidos en un espacio urbano, el Buen Vivir y los Bienes Comunes se presentan como un concepto que permite analizar la recuperación del espacio público como lugar y territorio significado. Así, el espacio público tiene la capacidad de contener estas dos corrientes, abriendo la posibilidad de dialogo entre el pensamiento decolonial y el pensamiento crítico. 
Tanto el Buen Vivir como los Bienes Comunes, entendido en una dimensión urbana material de reproducción social, si bien deben - o pueden- ser apropiadas y vividas por una cantidad 'limitada' de ciudadanos o comunidades (debido a sus dimensiones y escala territorial), en su concepto/esencia no representa límites, y puede entenderse como un espacio abierto en el sentido inmaterial. Por tanto, las luchas sociales de recuperación de los bienes y prácticas comunes, significa abrir nuevas posibilidades de ocupación, que se puede dar de forma diferenciada según las características locales de las ciudades y culturas. Esta diferenciación y reconocimiento de los lugares con sus trayectorias resquebraja también las dimensiones del espacio-tiempo y el desarrollo lineal del pensamiento moderno/colonizador.

Uno de los grandes desafíos que queda, es pensar en cómo reinventar el soporte material de las relaciones dentro del contexto local urbano, como nuevo hábitat que posibilite la reproducción de dinámicas colectivas y comunitarias.

\section{Referências}

ACOSTA, A. El Buen Vivir, Más allá del desarrollo. In: DELGADO RAMOS, G. C. (Coord.). Buena Vida, Buen Vivir: imaginarios alternativos para el bien común de la humanidad. México: UNAM, Centro de Investigaciones Interdisciplinarias en Ciencias y Humanidades, 2014. p. 21-60. ISBN 978-607-02-5400-0 (edición electrónica).

BARROS, R. De la teoría urbana a la crítica del capitalismo. In: GASIC, I.; NARVÁEZ, A.; QUIROZ, R (Comps). Reapropiaciones de Henry Lefebvre: Crítica, espacio y sociedad urbana. Santiago de Chile. Editorial triángulo, 2015. p. 56-71.

BOOKCHIN, M. Los límites de la ciudad. Madrid, España. Hermann Blume Ediciones. $1^{\circ} \mathrm{ed}$. 1978.

BOILLER, D. Pensar desde los comunes. Madrid, España. Traficantes de sueños, 2016.

BORJA, J.; CARRIÓN, F. Reflexiones en torno al Manifiesto por un Hábitat III alternativo. 2016. Disponible en: http://www.jordiborja.cat/manifiesto-habitat-alternativo/

BRENNER, N.; PECK, J.; THEODORE, N. Urbanismo neoliberal. La ciudad y el imperio de los mercados. In: El mercado contra la ciudad. Sobre globalización, gentrificación y políticas urbanas. Observatorio metropolitano de Madrid (org). Editorial traficantes de sueños. 2015

DELGADO RAMOS, G. C. Ciudad y Buen Vivir: ecología política urbana y alternativas para el bien común. Revista THEOMAI. Estudios críticos sobre sociedad y desarrollo. $\mathrm{N}^{\circ}$ 32. p. 36-56. Segundo semestre 2015. ISSN: 1515-6443. Disponible en: http://revistatheomai.unq.edu.ar/NUMERO_32/3_GianCarloDelgadoRamos_(theo32).pdf

Acceso en: 03 Abr. 2017. 
FARRÉS D, Y; MATARÁN R, A. Hacia una teoría urbana transmoderna y decolonial: una introducción. Polis, revista Latinoamericana: Educación. Contextos sociales y propensión a aprender. $\mathrm{N}^{\circ} 37$. p.1-20. 2014. ISSN: 0718-6568. Disponible en: http://polis.revues.org/9891 Acceso en: 30 septiembre 2016

GOMES, P.C.C. A condição urbana: ensaios de geopolítica da cidade. Rio de Janeiro: Bertrand Brasil, 2006.

GUDYNAS, E. Buen Vivir: Germinando alternativas al desarrollo. América Latina en movimiento, ALAI. N $\mathrm{N}^{\circ} 462 . \quad$ p. 1-20. Quito, Ecuador, 2011. Disponible en: http://www.alainet.org/es/active/48052. Visto en: Junio 2017.

GUDYNAS, E.; ACOSTA, A. El Buen Vivir o la disolución de la idea de progreso. In: ROJAS, M.(Coord.). La medición del progreso y del bienestar. Propuestas desde América Latina. México DF, 2011. p. 103-110.

HARVEY, D. Ciudades Rebeldes. Del derecho a la ciudad a la revolución Urbana. Madrid, España: Ediciones Akal, 2013.p.238.

HARVEY, D. El tipo de ciudad en que queremos vivir. Entrevista, 2013. In: Revista digital Sin Permiso. Disponível em: http://www.sinpermiso.info/

Visto: $25 / 07 / 2016$

JACOBS, J. Morte e vida das grandes cidades. São Paulo, Martin Fontes, 2000.

LANG, M. Desarrollo y alternativas al desarrollo. In: Encuentro de movimientos y organizaciones urbanas "Vivir Bien/Buen Vivir desde contextos urbanos". 2013. La Paz, Bolivia. 2013. p. 10-14. (Memoria Ponencia). Descargado de Fundación Rosa Luxemburgo: http://www.rosalux.org.ecles/actividades/eventos-de-aliados/738 memoriaencuentrourbano.html. Acceso en: 15 mayo 2017

LEFEBVRE, H. O direito à cidade. São Paulo, Brasil. Centauro editora. 2015.

MACAS, L. El Sumak Kawsay. In: HIDALGO C, L; GUILLEN G, A; DELEG G,N (Ed.). Sumak Kawsay Yuyay. Antología del pensamiento indigenista ecuatoriano sobre Sumak Kawsay. Huelva, España, 2014. p.179-192.

MARICATO, Erminia. As idéias fora do lugar e o lugar fora das ideias. Planejamento urbano no Brasil. In: ARANTES, O; VAINER, C; MARICATO, E. A cidade do pensamento único. Desmanchando consensos. Petrópolis, RJ: Editorial vozes, 2000.

MIGNOLO, Walter D. Historias locales/ diseños globales. Colonialidad, conocimientos subalternos y pensamiento fronterizo. Madrid, España: Ediciones Akal, 2003.

MOLINS,V. Moses, el demonio que transformó Nueva York. Disponible en: http://www.jotdown.es/2012/10/moses-el-demonio-que-transformo-nueva-york/.

Visto en: 05 julio de 2017.

POIRIER, Nicolás. Espacios públicos, espacios críticos. Prometeica, revista de filosofia y ciência. Año V, Núm. 11, invierno 2015, issn 1852-9488p.41-58 
PORTO-GONCALVES, C. W. De saberes y de territorios: diversidad y emancipación a partir de la experiencia latino-americana. Polis. Revista de la Universidad Bolivariana. v.8 $\mathrm{n}^{\circ}$ 22. p. 121-136. 2009 ISSN: 0718-6568.

RODRIGUEZ, M. Vivir Bien/Buen Vivir desde contextos urbanos. In: Encuentro de movimientos y organizaciones urbanas "Vivir Bien/Buen Vivir desde contextos urbanos". 2013. La Paz, Bolivia. 2013. p. 14-28. (Memoria Ponencia). Descargado de Fundación Rosa Luxemburgo:

http://www.rosalux.org.ec/es/actividades/eventos-de-aliados/738-memoriaencuentrourbano.html.

Acceso en: 15 mayo 2017

SANTOS, M. A urbanização Brasileira. São Paulo: HUCITEC. 1993.

SOLÓN, P. ¿Es posible Vivir Bien?. La Paz, Bolivia: Fundación Solón. 2016. 76 p.

SOUSA SANTOS, B. Descolonizar el saber, reinventar el poder. Montevideo, Uruguay: Ediciones trilce. 2010. p.110.

SOUZA, M. L. O território: sobre espaço e poder, autonomia e desenvolvimento; em Geografia: conceitos e temas; Iná Elias de Castro, Paulo Cesar da Costa Gomes, Roberto Lobato Correa (org). Rio de Janeiro; Bertrand Brasil, 2007.

SVAMPA, M. Pensar e desarrollo desde América Latina. Seminario Latinoamericano Derechos de la Naturaleza y Alternativas al extractivismo. Colectivo Voces de Alerta, CLAES, Jóvenes por la Igualdad y CEPPAS (Org.). Buenos Aires, noviembre de 2011. p. 125. Disponible en: http://www.maristellasvampa.net/archivos/ensayo56.pdf

SVAMPA, M. FRONTERA D. Revista digital. Entrevista. Maristella Svampa y la crisis del ciclo progresista en Latinoamérica. Visto en: 31 de Marzo 2016. Disponível em: http://www.fronterad.com/?q=maristella-svampa-y-crisis-ciclo-progresista-em latinoamerica

UN. A/conf.226/4. Conferencia de las Naciones Unidas sobre la Vivienda y el Desarrollo Urbano Sostenible, Hábitat III. Septiembre 2016.

Disponible en: http://www.habitat3.cl/wp-content/uploads/2016/10/Nueva-Agenda-UrbanaHabitat-III.pdf

VANHULST, J. El laberinto de los discursos del Buen Vivir: entre el Sumak Kawsay y el socialismo del siglo XXI. Polis, revista Latinoamerican. N$^{\circ} 40$. p.233-261. 2015. ISSN: 07186568. Disponible en: https://polis.revues.org/10727

WALSH, C. Interculturalidad, conocimientos y decolonialidad. In: Signo y pensamiento. v. XXIV, $n^{\circ}$ 46. p. 39-50. ISSN: 012-4823. Bogotá, Colombia: Enero-junio, 2005. Disponible en:http://www.redalyc.org/articulo.oa?id=86012245004

ZIBECHI, Raúl. Los trabajos colectivos como bienes comunes material/simbólicos. El Aplante, Revista de estudios comunitarios. Puebla, Mexico, $\mathrm{N}^{\circ} 1$ p.75-97. 2015. 